\title{
Numerical Modelling of the Temperature Distribution in a Two- Phase Closed Thermosyphon
}

\author{
Bandar Fadhl ${ }^{1,2}$, Luiz C. Wrobel ${ }^{1}$, Hussam Jouhara ${ }^{1}$ \\ ${ }^{1}$ School of Engineering and Design, Brunel University, Uxbridge, Middlesex UB8 3PH, UK \\ ${ }^{2}$ On leave from Department of Mechanical Engineering, Umm Al-Qura University, Makkah, KSA
}

Keywords: Thermosyphon, Computational fluid dynamics (CFD), Multiphase flow, Phase change material, Evaporation, Condensation

\begin{abstract}
A B S T R A C T
Interest in the use of heat pipe technology for heat recovery and energy saving in a vast range of engineering applications has been on the rise in recent years. Heat pipes are playing a more important role in many industrial applications, particularly in improving the thermal performance of heat exchangers and increasing energy savings in applications with commercial use. In this paper, a comprehensive CFD modelling was built to simulate the details of the twophase flow and heat transfer phenomena during the operation of a wickless heat pipe or thermosyphon, that otherwise could not be visualised by empirical or experimental work. Water was used as the working fluid. The volume of the fluid (VOF) model in ANSYS FLUENT was used for the simulation. The evaporation, condensation and phase change processes in a thermosyphon were dealt with by adding a user-defined function (UDF) to the FLUENT code. The simulation results were compared with experimental measurements at the same condition. The simulation was successful in reproducing the heat and mass transfer processes in a thermosyphon. Good agreement was observed between CFD predicted temperature profiles and experimental temperature data.
\end{abstract}

\section{INTRODUCTION}

A heat pipe is a two-phase heat transfer device with a highly effective heat transfer rate through evaporating and condensing a fluid that is circulating in a sealed container. A wickless heat pipe, or a two-phase closed thermosyphon, relies on gravitational forces to return the working fluid to the evaporator. This is different from a wicked heat pipe, where the working fluid is returned from the condenser by capillary forces [1-4]. Heat pipes have been successfully used for waste heat energy recovery in a vast range of engineering applications, such as heating, ventilation, and air conditioning (HVAC) systems [5], ground source heat pumps [6], water heating systems [7] and electronics thermal management [8]. This is mainly because of their simple structure, special flexibility, high efficiency, good compactness, and excellent reversibility [9-12]. Thermosyphons have three sections, which are the evaporator at the bottom end, where heat is added and the liquid is vaporised, the condenser at the top end, 
where heat is released and the vapour is condensed, and an adiabatic section in the middle between the evaporator and condenser [13].

In a thermosyphon, heat is added to the evaporator where a liquid pool exists, changing the liquid into vapour. The high temperature and pressure cause the vapour to flow and pass through the adiabatic section toward the condenser. The vapour adjacent to the condenser's wall gives up its latent heat that is absorbed in the evaporator section. The condensed liquid is then transported back to the evaporator due to gravity [14].

Two-phase closed thermosyphons have been extensively used in many applications [15]. However, only a limited number of CFD numerical simulation studies on two-phase closed thermosyphons have been published. Alizadehdakhel et al. [1] provided a two-dimensional model and experimental studies in which they investigated the effect of input heat flow and fill ratio of the working fluid on the performance of a two-phase closed thermosyphon. They validated their study using experimental results. Three input heat flow rates of 700, 500, and $350 \mathrm{~W}$ and three fill ratios of $0.3,0.5$, and 0.8 were considered. Under these operating conditions, they found the performance of the thermosyphon improved when the input heat flow was increased from 350 to 500W. Further, they discovered the best performance was at a fill ratio of 0.5 . The authors reported a term called "heat performance", which they calculated by using the following equation for different fill ratios:

$$
\eta=\frac{Q_{\text {out }}}{Q_{\text {in }}} \times 100
$$

However, this term is not usual in heat pipe publications. In general, the thermal performance term used to characterize thermodynamics at different heat throughputs is the total thermal resistance.

Legierski et al. [14] provided CFD modelling and experimental measurements of heat and mass transfer in a horizontal wicked heat pipe. They investigated the effectiveness of the heat pipe thermal conductivity in a transient state during start-up of the pipe operation and during temperature increases. The authors used a heat pipe that was $200 \mathrm{~mm}$ long with $4 \mathrm{~mm}$ diameter and $25 \mathrm{~mm}$ length for the evaporator and condenser. They also used two containers, one for hot water $\left(90^{\circ} \mathrm{C}\right)$ at the evaporator section and one for cold water (ambient temperature) at the condenser section. They developed a three-dimensional CFD model to simulate the internal vapour flow. They found that the effective thermal conductivity of the wicked heat pipe depended on the time in the range between $15 \times 10^{3}$ and $30 \times 10^{3} \mathrm{~W} / \mathrm{m} \mathrm{K}$, and achieved its steady-state value after approximately 20 to 30s. However, the authors did not consider in the CFD modelling the phase change material from liquid phase to vapour phase, as well as condensation in the condenser section and pool boiling in the evaporator section.

Zhang et al. [16] developed a two-dimensional heat and mass transfer model for a diskshaped flat two-phase thermosyphon used in electronics cooling. The authors simulated the vapour flow inside the flat two-phase thermosyphon as a single-phase flow. They compared their predicted model with experimental results to determine the factors that affected the axial 
thermal resistance of a thermosyphon. This model was limited as it considered the flow inside the flat thermosyphon as a pure vapour phase only.

Joudi and Al-Tabbakh [17] numerically studied a two-phase thermosyphon solar domestic hot water system, by using a computer simulation. They used R-11 as a working fluid in the thermosyphon. Firstly, the authors validated the computer program and calculation procedure by comparing the results with those obtained with single-phase systems. They then performed calculations for the two-phase thermosyphon system. In their calculations, they evaluated mass flow rate, saturation pressure, and temperature in the collector and condenser, together with tank temperature and collector and condenser thermal efficiencies. The results of the study showed that the collector efficiency of the two-phase system was approximately $20 \%$ greater than in a single-phase system. Further, the response of the two-phase system in reaching maximum tank temperature and efficiency was faster than in a single phase system. This study was only a mathematical model and did not include any flow visualisation.

Annamalai and Ramalingam [18] carried out an experimental investigation and CFD analysis of a wicked heat pipe using ANSYS CFX. The authors considered the region inside the heat pipe as a single phase of vapour and a wick region as the liquid phase. They compared the predicted surface temperature along the evaporator and condenser walls and the vapour temperature inside the heat pipe with the experimental data. This model treated the flow inside the heat pipe as a single-phase and did not include the evaporation, condensation and phase change processes.

De Schepper et al. [19] developed a model to simulate the evaporation process of a hydrocarbon feedstock in a heat exchanger. They used the VOF and UDF techniques to simulate flow boiling including the phase change process. They proposed correlations to calculate the mass and heat transfer between the phases that were able to simulate the evaporation and boiling phenomena inside the convection section of a steam cracker. This model was for the convection section in a steam-cracking furnace; however, it did not include the heat pipe system.

Lin et al. [20] built a CFD model to predict the heat transfer capability of miniature oscillating heat pipes. The effects of different heat transfer lengths and inner diameters at different heat inputs were used to analyse the heat transfer capability of MOHPs. They compared the predicted model with experimental results. This model did not visualise the internal phenomena of evaporation, condensation and phase change inside the MOHPs.

Heat pipe technology is currently still under development. However, there are limited studies on the validation of predictions for modelling closed two-phase thermosyphons or wickless heat pipes. Further, a CFD simulation of a wickless heat pipe that considers all the details of heat transfer phenomena inside the heat pipe has not yet been reported. Hence, a gap still exists for further CFD work to model a wickless heat pipe. Additionally, CFD models can reduce the amount of experimental work. Therefore, in this paper, a comprehensive CFD modelling has been employed to cover all details of two-phase flow and heat transfer phenomena during the operation of a straight wickless heat pipe. Moreover, a user-defined function (UDF) has been used to complete the FLUENT code in order to simulate the phase change material. 
In order to validate the CFD findings, an experimental apparatus was built to carry out a thermal performance investigation on a typical wickless heat pipe.

The experimental apparatus used in the current investigation is shown in Figure 1. The apparatus consists of a two-phase closed thermosyphon (TPCT), a rope heater, the cooling water circuit, and instrumentation. The apparatus was fixed on a framework to insure vertical orientation under all test conditions.

The TPCT was manufactured from a $22 \mathrm{~mm}$ outer diameter, $0.5 \mathrm{~m}$-long smooth copper tube with a wall thickness of $0.9 \mathrm{~mm}$. It consists of a $0.2 \mathrm{~m}$-long evaporator section, a $0.1 \mathrm{~m}$-long adiabatic section and a $0.2 \mathrm{~m}$-long condenser section (see Figure 1).

The evaporator section was heated by a rope heater with a maximum power output of $500 \mathrm{~W}$ at 220V, which was evenly wrapped and not directly positioned above any of the thermocouples that are used to measure the surface temperature of this section. The energy output of the heater was controlled by a variac. The evaporator section was wrapped in a layer of fire-proof insulation before it was wrapped with suitable thermal insulation layers to minimise any heat losses to the ambient. The condenser section was cooled using a double pipe concentric heat exchanger with an insulated outer surface. The $10-\mathrm{cm}$ long adiabatic section was also well insulated to ensure no heat energy interactions take place with the ambient. The insulated adiabatic section wall temperature was used as an indicator of the TPCT working temperature. The TPCT was charged with triple-distilled and degassed water at a $50 \%$ evaporator filling ratio.

The cooling water circuit provided the heat exchanger of the condenser section with water at predefined conditions for the inlet temperature and flow velocity. The water was supplied through a constant-head water circuit to ensure constant mass flow rate through the condenser's heat exchanger. The heat from the water leaving the heat exchanger was removed in a secondary reservoir, using a chilled water coil, before it was returned to the main tank using a dedicated pump. A proportional-integral-derivative control system (PID) was used to control the chiller system to ensure water supply at the heat exchanger inlet was constant throughout the testing programme. A flow meter and a valve arrangement were used to control and measure the inlet volume flow rate into the shell of the heat exchanger.

The experimental apparatus was equipped with calibrated instrumentations to measure the power throughputs, temperatures and flow rate data.

The temperature distribution along the TPCT was monitored using eight thermocouples. As shown in Figure 1, two thermocouples, labelled as $\mathrm{Te}_{1}$ and $\mathrm{Te}_{2}$ were used to monitor the evaporator section and were placed $40 \mathrm{~mm}$ and $160 \mathrm{~mm}$ from the bottom. Another thermocouple, labelled as Ta, was positioned at the centre of the adiabatic section, while the condenser section was monitored using five, evenly spaced, thermocouples, labelled as $\mathrm{Tc}_{1}$ to $\mathrm{T}_{5}$. These five thermocouples were also used to confirm the non-existence of non-condensable 
gases (NCGs) within the heat pipes throughout the conducted tests. Two additional thermocouples were also used to monitor the input and the output water temperatures from the heat exchanger. These two thermocouples were stainless steel shielded and were positioned at the centre of the flow using two compression fittings.

All of the thermocouples were $\mathrm{K}$-type $(\mathrm{NiCr} / \mathrm{NiAl})$ and were read and monitored using a 32-channel DataScan system, which was connected to a dedicated PC for an online data recording at $1 \mathrm{~Hz}$ scanning frequency. The cooling water flow rate was measured using an inline flow meter.

\section{EXPERIMENTAL PROCEDURE}

At the start of each experiment, and after fixing the water flow rate to the desired value, the electrical heat input was set at its minimum level of 50W. The equipment was then allowed to stabilise for 30 minutes prior to any readings being taken. Temperature readings, from all the rig thermocouples, were then monitored for two hours, using the datalogger. The two-hour monitoring period was designed to ensure that no degrading of performance was taking place during operation. The procedure was repeated for various electrical input powers between 50 and $500 \mathrm{~W}$ with an increment of 50W. Each test was repeated three times for each power setting to confirm repeatability. The repeated tests were done after the whole power range was covered to confirm stable thermal characteristics of the TPCT after a prolonged operational time.

\subsection{Data reduction}

The effective overall thermal resistance of the TPCT was calculated by applying the electrical analogue in the form:

$$
R_{E X P}=\frac{\Delta T_{e-c}}{Q}
$$

here $\Delta T_{e-c}=T_{e_{-} a v}-T_{c_{-} a v} ; \quad T_{e_{-} a v}=\frac{T_{e 1}+T_{e 2}}{2}$ and $T_{c_{-} a v}=\frac{\sum_{j=1 \rightarrow 5} T_{c j}}{5}$ are the average internal wall temperatures in the evaporator and condenser sections, respectively, and Q is the power throughput. The internal wall temperatures of the TPCT were measured after considering the thermal conduction across the shell wall. 


\subsection{Uncertainty analysis}

The main source of uncertainty for the calculated $R$ came from the temperature readings, which were measured using K-type thermocouples with a measurement uncertainty of $\pm\left(0.05 \% \mathrm{rdg}+0.3^{\circ} \mathrm{C}\right)$ and $0.5 \% \mathrm{rdg}$ for the power readings.

According to Taylor [21], the propagation of uncertainties associated with the calculated $R$ $\left(S_{R}\right)$ can be estimated from the equation:

$$
S_{R}=R \sqrt{\left(\frac{S_{\Delta T_{e-c}}}{\Delta T_{e-c}}\right)^{2}+\left(\frac{S_{Q}}{Q}\right)^{2}}
$$

where:

$S_{\Delta T_{e-c}}=\sqrt{S_{T_{e_{-} a v}}{ }^{2}+S_{T_{c_{-} a v}}^{2}}$ : The uncertainty associated with $\Delta T_{e-c}$

$S_{Q_{\text {in }}}$ : The uncertainty associated with the reading of the energy throughput $Q$

By calculating $S_{R}$, for the entire experimental range, the maximum uncertainty associated with the resulting $R$ values was found to be around 5.5\%, which is an acceptable value in engineering applications.

\section{MODEL DESCRIPTION}

In this model, the commercial code ANSYS FLUENT 13.0 and the Volume of Fluid (VOF) method have been applied for the modelling of a closed two-phase thermosyphon. There are two main approaches to the numerical calculations of multiphase flows, which are the Euler-Lagrange approach and the Euler-Euler approach. The Euler-Lagrange approach treats the fluid phase as a continuum and a dispersed phase such as bubbles or droplets as a second phase, in which the dispersed-phase volume fractions are not to exceed $10 \%$. As the current application considers the volume fraction of the second phase exceeds $10 \%$, the EulerEuler approach has been adopted as it uses the idea of phasic volume fraction in which the volume of a phase cannot be occupied by the other phases. These volume fractions are assumed to be continuous functions of space and time [22].

\subsection{Volume of fluid (VOF) model}

Numerical solutions based on the finite volume method are more difficult for multiphase flows than for a single-phase flow. The reasons for this difficulty are that the interfaces between the phases are not stationary and physical properties such as density and viscosity 
change at the interfaces between the different phases, which requires an intensive computational effort. The volume of fluid (VOF) technique, therefore, has been used to solve these problems by determining the motion of all phases and defining the motion of the interfaces indirectly from this result $[19,23,24]$.

The VOF technique can be applied to model two immiscible fluids with a clearly defined interface between the phases, and is used for surface-tracking applied to a fixed mesh. In the VOF model, one set of Navier-Stokes equations are solved through the computational domain and used to track the motion of the different phases by defining the volume fraction of each phase [22]. The VOF model relies on the fact that each cell in the domain is occupied by one phase or a combination of the two phases. In other words, if $\alpha_{\mathrm{L}}$ is a volume fraction of liquid and $\alpha_{V}$ is a volume fraction of vapour, the following three conditions are possible:

- $\quad \alpha_{\mathrm{L}}=1$ : The cell is fully occupied by liquid

- $\alpha_{\mathrm{L}}=0$ : The cell is fully occupied by vapour

- $0<\alpha_{\mathrm{L}}<1$ : The cell is at the interface between the liquid and vapour phases

When the third condition occurs, the volume fractions of all phases sum to unity [22].

\section{$4.2 \quad$ Navier-Stokes equations for VOF model}

The governing equations of mass continuity, momentum and energy are used to describe the motion of the working fluid in a thermosyphon. This will be explained in the next section.

\subsubsection{Continuity equation for VOF model (Volume fraction equation)}

By applying the physical principle of conservation of mass to the fluid, the continuity equation has the following form:

$$
\nabla \cdot(\rho \vec{u})=-\frac{\partial \rho}{\partial t}
$$

where $\rho$ is the density, $\mathrm{u}$ is the velocity and $\mathrm{t}$ is the time.

Solution of the above equation for the volume fraction of one of the phases is used to track the interface between the phases. Thus, the continuity equation of the VOF model for the secondary phase (L) can be expressed as:

$$
\nabla \cdot\left(\alpha_{L} \rho_{L} \vec{u}\right)=-\frac{\partial}{\partial t}\left(\alpha_{L} \rho_{L}\right)+S_{m}
$$

where $S_{m}$ is the mass source term used to calculate the mass transfer during evaporation and condensation.

The continuity equation shown above can be called the volume fraction equation and this equation will not be solved for the primary phase; the primary-phase volume fraction is computed based on the following constraint: 


$$
\sum_{L=1}^{n} \alpha_{L}=1
$$

When the cell is not fully occupied by the primary phase (V) or the secondary phase (L), a mixture of the phases $\mathrm{L}$ and $\mathrm{V}$ exist. Thus, the density of the mixture is given as the volume-fraction-averaged density and takes the following form:

$$
\rho=\alpha_{L} \rho_{L}+\left(1-\alpha_{L}\right) \rho_{V}
$$

\subsubsection{Momentum equation for VOF model}

The forces acting in the fluid were considered to be gravitational, pressure, friction and surface tension. In order to consider the effect of surface tension along the interface between the two phases, the continuum surface force (CSF) model proposed by Brackbill et al. [25] has been added to the momentum equation

$$
F_{C S F}=2 \sigma_{L V} \frac{\alpha_{L} \rho_{L} C_{V} \nabla \alpha_{V}+\alpha_{V} \rho_{V} C_{L} \nabla \alpha_{L}}{\rho_{L}+\rho_{V}}
$$

where $\sigma_{L V}$ is the surface tension coefficient and $\mathrm{C}$ is the surface curvature.

By taking into account the above forces, the momentum equation for the VOF model takes the following form:

$$
\frac{\partial}{\partial t}(\rho \vec{u})+\nabla \cdot(\rho \bar{u} \vec{u})=\rho \vec{g}-\nabla p+\nabla \cdot\left[\mu\left(\nabla \vec{u}+\nabla \vec{u}^{T}\right)-\frac{2}{3} \mu \nabla \cdot u I\right]+F_{C S F}
$$

where $\mathrm{g}$ is the acceleration of gravity, $\mathrm{p}$ is the pressure, and I is the unit tensor.

The momentum equation depends on the volume fraction of all phases through the physical properties of density and viscosity. Thus, the dynamic viscosity $\mu$ is given by

$$
\mu=\alpha_{L} \mu_{L}+\left(1-\alpha_{L}\right) \mu_{V}
$$

A single momentum equation is solved throughout the computational domain, and the calculated velocity is shared among the phases.

\subsubsection{Energy equation for VOF model}

The energy equation for the VOF model has the following form: 


$$
\frac{\partial}{\partial t}(\rho e)+\nabla \cdot(\rho e \vec{u})=\nabla \cdot(k \cdot \nabla T)+\nabla \cdot(p \vec{u})+S_{E}
$$

where $S_{E}$ is the energy source term used to calculate the heat transfer during evaporation and condensation.

The VOF model treats the temperature $\mathrm{T}$ as a mass-averaged variable and the thermal conductivity is calculated as:

$$
k=\alpha_{L} k_{L}+\left(1-\alpha_{L}\right) k_{V}
$$

The VOF model also treats the internal energy $e$ as a mass-averaged variable in the following form:

$$
e=\frac{\alpha_{L} \rho_{L} e_{L}+\alpha_{V} \rho_{V} e_{V}}{\alpha_{L} \rho_{L}+\alpha_{V} \rho_{V}}
$$

where $e_{L}$ and $e_{V}$ are based on the specific heat $c_{p}$ of the phase and the shared temperature, given by the caloric equation of state:

$$
\begin{aligned}
& e_{L}=c_{p, L}\left(T-T_{\text {sat }}\right) \\
& e_{V}=c_{p, V}\left(T-T_{\text {sat }}\right)
\end{aligned}
$$

A single energy equation is also solved throughout the domain for both phases, and the calculated temperature is shared among the phases.

\subsection{Mass and heat transfer during the evaporation and condensation processes}

FLUENT does not have the ability to simulate the phase change material during the evaporation and condensation processes. In order to circumvent this problem, a user-defined function (UDF) has been used to complete the existing FLUENT code. This UDF is essentially required to calculate the mass and heat transfer between the liquid and vapour phases during the evaporation and condensation processes, determined by the source terms in the governing equations, particularly the continuity and energy equations. Source terms proposed by De Schepper et al. [19] have been used to calculate the mass and energy transfer. Mass sources, $S_{M}$ in the volume fraction equation and energy sources, $S_{E}$ in the energy equation used in the present work can be found in Table 1 , where $T_{\text {mix }}$ and $T_{\text {sat }}$ are the mixture temperature and saturation temperature, respectively, and LH stands for latent heat. 
Mass and energy sources in Table 1 have been implemented in the UDF and linked to the governing equations in FLUENT. The volume fraction for each phase in the cell has been defined by the VOF model. Therefore, the evaporation process required two mass sources for the calculation of the mass transfer, Eq. (15) describing the amount of mass taken from the liquid phase and Eq. (16) describing the amount of mass added to the vapour phase. The same procedure takes place for the condensation process, Eq. (17) and Eq. (18) describing the amount of mass transfer from vapour to liquid phase.

For heat transfer, a single source term for both phases is required in the evaporation or condensation. Calculation of heat transfer has been determined by multiplying the mass source with the latent heat for evaporation or condensation, Eq. (19) and Eq. (20), respectively.

Furthermore, it can be seen in Table 1 that the temperature is introduced as a mixture temperature rather than liquid or vapour temperature. The reason as mentioned before is that the VOF model associates some variables such as temperature and velocity with the mixture phase, not with a specific phase.

\section{SIMULATION MODEL}

A two-dimensional model was developed to simulate the two-phase flow and heat transfer phenomena in a thermosyphon. A total length of $500 \mathrm{~mm}$ of a closed copper tube, as can be seen in Figure 1, is used as the thermosyphon geometry, with 22 and $20.2 \mathrm{~mm}$ for the outer and inner diameters, respectively. According to the experimental condition, the thermosyphon was divided into three sections represented by the evaporator and condenser sections, with an adiabatic section between them. Both evaporator and condenser have $200 \mathrm{~mm}$ length, while the adiabatic section has $100 \mathrm{~mm}$ length.

The temperature distribution along the outer wall of the thermosyphon was monitored using eight different positions, which are the thermocouple positions as shown in Figure 2. According to the experimental setup, $\mathrm{Te}_{1}$ and $\mathrm{Te}_{2}$ were used to record the average temperature of the evaporator section, while $\mathrm{Tc}_{1}$ to $\mathrm{Tc}_{5}$ were used to record the average temperature of the condenser section. Ta was used to record the average temperature of the adiabatic section.

Different mesh sizes were used to test grid independence. The average temperature of the evaporator ( $\left.\mathrm{T}_{\text {evap av }}\right)$ and condenser ( $\mathrm{T}_{\text {cond av }}$ ) sections for different mesh sizes were monitored and are shown in Table 2. For the heating power of $172.87 \mathrm{~W}$, it was found that almost the same temperature differences between the evaporator and condenser sections were obtained for different mesh sizes. As a result, the mesh size of 69,092 Quad, Map cells was selected for the simulation analysis. Near the left and right walls, five layers of cells are used in order to capture the thin liquid film that develops near the wall, as shown in Figure 3. One cell layer has been used for the upper and bottom walls, as no heat conduction is considered through these walls. 
A non-slip boundary condition is imposed at the inner walls of the thermosyphon. In order to simulate the heating and evaporation, a constant heat flux is defined at the wall boundaries of the evaporator section, depending on the power input. A zero heat flux is defined as boundary condition on the adiabatic section, assuming this section is insulated. The condenser section is cooled as a result of heat released when vapour condenses. It is assumed that the condenser is cooled by water, according to the experimental apparatus. Thus, a convection heat transfer coefficient is defined as boundary condition on the condenser's wall. The corresponding heat transfer coefficients have been calculated using the formula:

$$
h_{c}=\frac{Q_{c}}{2 \pi r L_{c}\left(T_{c, a v}-T_{\infty}\right)}
$$

where $h_{c}$ is the condenser heat transfer coefficient, $Q_{c}$ is the rate of heat transfer from the condenser, $L_{c}$ is the condenser height, $T_{c, a v}$ is the condenser average temperature and $T_{\infty}$ is the average temperature of the condenser cooling water. The values of $T_{\infty}, Q_{c}$ and $T_{c, a v}$ in the above equation and in Table 3 come from the experiments. The condenser heat transfer coefficients are determined based on the experimental data, and are shown in Table 3.

The effect of surface tension along the interface between the two phases is included by using the following equation, driven from the steam table:

$$
\sigma_{L V}=0.09805856-1.845 \times 10^{-5} T-2.3 \times 10^{-7} T^{2}
$$

where $\mathrm{T}$ is the shared temperature.

The model considered water as the working fluid with a fill ratio of 0.5 (the ratio of initial liquid volume per total volume of the evaporator) and the following equation driven from the steam table is used for their density:

$$
\rho_{L}=859.0083+1.252209 T-0.0026429 T^{2}
$$

Figure 4 illustrates the boundary conditions implemented to the computational model.

\section{SOLUTION STRATEGY AND CONVERGENCE CRITERION}

A transient simulation with a time step of $0.0005 \mathrm{~s}$ is carried out to model the dynamic behaviour of the two-phase flow. The time step has been selected based on the Courant number, which is the ratio of the time step to the time a fluid takes to move across a cell. For VOF models, the maximum Courant number allowed near the interface is 250 [26]. For a time 
step of 0.0005 , the Courant number is less than 3 . The simulation reaches a steady state after around $60 \mathrm{~s}$.

A combination of the SIMPLE algorithm for pressure-velocity coupling and a first-order upwind scheme for the determination of momentum and energy is included in the model. GeoReconstruct and PRESTO discretization for the volume fraction and pressure interpolation scheme, respectively, are also performed in the simulation. In the present studies, the numerical computation is considered to have converged when the scaled residual of the mass and velocity components is less than $10^{-4}$.

Water vapour is defined as the primary (vapour) phase and water liquid is defined as the secondary (liquid) phase. For the calculation of the mass and heat transfer during the evaporation and condensation processes, a temperature of $373 \mathrm{~K}$ is used as the boiling temperature and the latent heat in the UDF code is $2455 \mathrm{~kJ} / \mathrm{kg}$. When the simulation is started, the liquid pool in the evaporator is heated first. Once the saturation temperature (373K) is reached, evaporation starts and phase change occurs. The saturated vapour is then transported upward to the condenser, where it condenses along the colds walls forming a thin liquid film.

\section{SIMULATION RESULTS}

The simulation results of the boiling and condensation processes in the thermosyphon reached a quasi-steady state after around $60 \mathrm{~s}$. The temperature distribution along the outer wall of the thermosyphon for heating powers of $172.87 \mathrm{~W}$ and $376.14 \mathrm{~W}$ are shown in Tables 4 and 5, respectively. Eight different positions have been used to monitor the average temperature for the evaporator, adiabatic and condenser sections. Table 6 shows the surface average temperatures in the evaporator $\left(\mathrm{Te} \mathrm{av}_{\mathrm{v}}\right)$, adiabatic $(\mathrm{Ta})$ and condenser $\left(\mathrm{Tc}_{\mathrm{av}}\right)$ sections, in addition to the thermal resistance of the system and the relative error $\left(R_{E}\right)$ between CFD simulation and experimental results (EXP). The simulation results of the VOF model showed the same trend as the experimental data. The average relative error of evaporator, adiabatic and condenser average temperatures are $7.9 \%, 9.9 \%$ and $1.9 \%$, respectively.

Figure 5 shows the experimental and simulation results of the outer surface temperature distribution along the thermosyphon for different heat inputs. The distance between 0 and 200 $\mathrm{mm}$ indicates the evaporator section. The distance between 200 and $300 \mathrm{~mm}$ indicates the adiabatic section, while the distance between 300 and $500 \mathrm{~mm}$ indicates the condenser section. The predicted CFD evaporator average temperature has deviated from the experimental results due to the consideration of a continuous heat power input along the length of the evaporator section where, in the experiment, a wire heater is evenly wrapped around the evaporator section to ensure it was not directly above a thermocouple. As shown in Figure 5, the condenser section temperature shows better agreement with the experimental results. As a result of no heat loss in the adiabatic section, the temperature is raised in the surface of this section due to the axial conduction heat transfer.

\subsection{Performance of a closed two-phase thermosyphon}

The performance of a thermosyphon can be characterised by the overall thermal resistance. The overall rate of heat transfer to the system $\dot{Q}$ is proportional to the effective 
temperature difference between the heat source to the evaporator and the heat sink from the condenser, and inversely proportional to the equivalent thermal resistance to heat transfer between the two regions. The overall rate of heat transfer can be defined as:

$$
\dot{Q}=\frac{\Delta T}{R}
$$

Hence, the effective overall thermal resistance of a thermosyphon $R$ is calculated using the following equation:

$$
R_{C F D}=\frac{T e_{a v C F D}-T c_{a v C F D}}{Q_{i n}}
$$

where $\mathrm{Te}_{\mathrm{av}} \mathrm{CFD}$ and $\mathrm{TC}_{\mathrm{av}}$ CFD are the average temperature in the evaporator and condenser, respectively, and $\mathrm{Q}_{\text {in }}$ is the heating power input. Different heating power inputs have been used to investigate the performance of a closed two-phase thermosyphon. Figure 6 illustrates that the predicted thermal resistance is in good agreement with the experimental data as the thermal resistance of the thermosyphon decreases with increasing heating power load. For heating powers above $170 \mathrm{~W}$, the thermal resistance stays relatively independent of the heating power input rate. For lower heating inputs, the thermal resistance tends to increase. In summary, the CFD simulation results are able to show the variation trends of the thermal performance of the thermosyphon for different heat throughputs.

\section{FLOW VISUALISATION OF CFD SIMULATION}

Figures 7 and 8 show the volume fraction contours of pool boiling in the evaporator and condensed liquid film in the condenser, respectively, for a heating power of $172.87 \mathrm{~W}$. A red colour illustrates the presence of only vapour (vapour volume fraction $=1$ ), while a blue colour stands for the presence of only liquid (vapour volume fraction $=0$ ). In Figure 8, focus is made on the condensed liquid film in the lower region of the condenser. At the beginning of the process, the liquid pool that initially filled half of the evaporator was heated by imposing a constant heat input. At positions where the liquid reached the boiling temperature, the liquid starts to evaporate and phase change occurs as shown in Figure 7. This continuous evaporation of liquid results in a decrease in the liquid volume fraction and an increase of the vapour volume fraction. At those positions where the liquid evaporates, bubbles are formed and transported toward the top region of the liquid pool.

Following the above process, saturated vapour is transported upward to the condenser. As the vapour reaches the condenser's wall, where a convection heat transfer coefficient boundary condition is defined, as shown in Table 3, the vapour condenses along the cold walls forming filmwise condensation as shown in Figure 8. This liquid will then fall back to the evaporator section and recharge the liquid pool.

As shown in Figure 9, the temperature contours during the thermosyphon operation have been recorded. The heating power is $172.87 \mathrm{~W}$. At the beginning, the temperature in the evaporator section increased due to the heating power input, as shown in Figure 9 ( $0.5 \mathrm{~s}$ and 1 
s). When the temperature of the evaporator section reached the boiling temperature, the phase change begins. The region of high temperature in the evaporator section expands due the vapour moving upward, as shown in Figure 9 (1.5 s to $3 \mathrm{~s})$. As the heating power in the evaporator section continues, the vapour flows across the adiabatic section to the condenser section, as shown in Figure 9 ( $4 \mathrm{~s}$ and $5 \mathrm{~s}$ ). Then, a high temperature region appears in the condenser section due to the vapour reaching this section, as shown in Figure 9 (10 s). The high temperature of the condenser section starts to decrease, corresponding to vapour condensing to liquid and, with the help of gravity, the condensed liquid falls back to the evaporator section. The above cycle describes the process of heat transfer during the operation of the thermosyphon. After that, the temperature distribution inside the thermosyphon becomes uniform as shown in Figure 9 (30 s to $60 \mathrm{~s}$ ).

\section{CONCLUSIONS}

The main objective of this work is the development of a CFD model that allows to perform simulations of the evaporation and condensation phenomena in a thermosyphon. The simulation of these processses is one of the steps required to model the complete system in order to consider the phase change material by implementing the appropriate source terms in the flow governing equations. These source terms, determining the mass and heat transfer between the liquid and vapour phases, have been linked to the main hydrodynamic equations of FLUENT.

The CFD results of this work show that FLUENT with the VOF method can successfully model the complex phenomena inside the thermosyphon. From the flow visualisation, it is found that the CFD simulation was able to reproduce the operation of the thermosyphon, including the pool boiling in the evaporator section and the condensed liquid film in the condenser section.

The average surface temperature along the thermosyphon has been compared with the experimental results at the same condition, showing that the predicted results agreed with the experimental results quite well. The thermal performance of the thermosyphon has also been characterised at different heat throughputs by the effective overall thermal resistance, and it is found that increasing the heating power inputs above $172 \mathrm{~W}$ has improved the thermal performance of thermosyphon.

\section{Acknowledgment}

The first author deeply appreciates the financial support provided by the Saudi Cultural Bureau in London, the Ministry of Higher Education and the Mechanical Engineering Department, Umm Al-Qura University. 


\section{References}

[1] Alizadehdakhel A, Rahimi M, Alsairafi AA. CFD modeling of flow and heat transfer in a thermosyphon. International Communications in Heat and Mass Transfer 2010; 37: 312-318.

[2] ESDU. Heat pipes - general information on their use, operation and design. ESDU Manual 80013 1980.

[3] Faghri A. Heat Pipe Science and Technology, Taylor \& Francis: Washington, D.C., 1995.

[4] Dunn P, Reay DA. Heat Pipes, Pergamon Press: New York, 1994.

[5] Kerrigan K, Jouhara H, O'Donnell GE, Robinson AJ. Heat pipe-based radiator for low grade geothermal energy conversion in domestic space heating. Simulation Modelling Practice and Theory 2011; 19: 1154-1163.

[6] Jouhara H, Meskimmon R. Experimental investigation of wraparound loop heat pipe heat exchanger used in energy efficient air handling units. Energy 2010; 35: 4592-4599.

[7] Mathioulakis E, Belessiotis V. A new heat-pipe type solar domestic hot water system. Solar Energy 2002; 72: 13-20.

[8] Weng Y-, Cho H-, Chang C-, Chen S-. Heat pipe with PCM for electronic cooling. Applied Energy 2011; 88: 1825-1833.

[9] Jouhara H. Economic assessment of the benefits of wraparound heat pipes in ventilation processes for hot and humid climates. International Journal of Low-Carbon Technologies 2009; 4: 52-60.

[10] Parand R, Rashidian B, Ataei A, Shakiby K. Modeling the transient response of the thermosyphon heat pipes. Journal of Applied Sciences 2009; 9: 1531-1537.

[11] Ochsner K. Carbon dioxide heat pipe in conjunction with a ground source heat pump (GSHP). Applied Thermal Engineering 2008; 28: 2077-2082.

[12] Du J, Bansal P, Huang B. Simulation model of a greenhouse with a heat-pipe heating system. Applied Energy 2012; 93: 268-276.

[13] Cengel YA. Heat Transfer : A Practical Approach. McGraw-Hill: Boston; Toronto, 2003.

[14] Legierski J, Wiecek B, de Mey G. Measurements and simulations of transient characteristics of heat pipes. Microelectronics and Reliability 2006; 46: 109-115.

[15] Jiao B, Qiu LM, Zhang XB, Zhang Y. Investigation on the effect of filling ratio on the steady-state heat transfer performance of a vertical two-phase closed thermosyphon. Applied Thermal Engineering 2008; 28: 1417-1426.

[16] Zhang M, Liu Z, Ma G, Cheng S. Numerical simulation and experimental verification of a flat twophase thermosyphon. Energy Conversion and Management 2009; 50: 1095-1100. 
[17] Joudi KA, Al-Tabbakh AA. Computer simulation of a two phase thermosyphon solar domestic hot water heating system. Energy Conversion and Management 1999; 40: 775-793.

[18] Annamalai AS, Ramalingam V. Experimental investigation and computational fluid dynamics analysis of a air cooled condenser heat pipe. Thermal Science 2011; 15: 759-772.

[19] De Schepper SCK, Heynderickx GJ, Marin GB. Modeling the evaporation of a hydrocarbon feedstock in the convection section of a steam cracker. Computers \& Chemical Engineering 2009; 33: 122-132.

[20] Lin Z, Wang S, Shirakashi R, Winston Zhang L. Simulation of a miniature oscillating heat pipe in bottom heating mode using CFD with unsteady modeling. International Journal of Heat and Mass Transfer 2013; 57: 642-656.

[21] Taylor JR. An Introduction to Error Analysis: The Study of Uncertainties in Physical Measurements. University Science Books: Sausalito, 1997.

[22] ANSYS FLUENT Theory Guide (Release 13.0). Multiphase Flows. ANSYS, Inc., November 2010, (chapter 17), pp. 455-568.

[23] Versteeg HK, Malalasekera W. An Introduction to Computational Fluid Dynamics; The Finite Volume Method. Prentice-Hall: Harlow, Second ed., 2007.

[24] Anderson JD. Computational Fluid Dynamics The Basics with Applications. McGraw-Hill: New York, 1995.

[25] Brackbill JU. A continuum method for modeling surface tension. Journal of Computational Physics 1992; 100: 335-354.

[26] ANSYS FLUENT User Guide (Release 13.0). Modelling Multiphase Flows. ANSYS, Inc., November 2010, (chapter 26), pp. 1143-1144. 


\section{Tables}

Table 1: Construction of mass and energy sources [19]

\begin{tabular}{|c|c|c|c|c|}
\hline $\begin{array}{l}\text { Thermal } \\
\text { Energy }\end{array}$ & $\begin{array}{c}\text { Phase Change } \\
\text { process }\end{array}$ & $\begin{array}{c}\text { Temp. } \\
\text { Condition } \\
\end{array}$ & Phase & Source Term \\
\hline \multirow{4}{*}{$\begin{array}{l}\text { Mass } \\
\text { Transfer }\end{array}$} & \multirow{2}{*}{ Evaporation } & \multirow{2}{*}{$\mathrm{T}_{\text {mix }}>\mathrm{T}_{\mathrm{sat}}$} & Liquid & $S_{M}=-0.1 \rho_{L} \alpha_{L} \frac{T_{\text {mix }}-T_{\text {sat }}}{T_{\text {sat }}}(15)$ \\
\hline & & & Vapour & $S_{M}=0.1 \rho_{L} \alpha_{L} \frac{T_{m i x}-T_{s a t}}{T_{s a t}}$ \\
\hline & \multirow{2}{*}{ Condensation } & \multirow{2}{*}{$\mathrm{T}_{\text {mix }}<\mathrm{T}_{\text {sat }}$} & Liquid & $S_{M}=0.1 \rho_{V} \alpha_{V} \frac{T_{\text {sat }}-T_{\text {mix }}}{T_{\text {sat }}}$ \\
\hline & & & Vapour & $S_{M}=-0.1 \rho_{V} \alpha_{V} \frac{T_{\text {sat }}-T_{\text {mix }}}{T_{\text {sat }}}$ \\
\hline \multirow{2}{*}{$\begin{array}{l}\text { Heat } \\
\text { Transfer }\end{array}$} & Evaporation & $\mathrm{T}_{\text {mix }}>\mathrm{T}_{\text {sat }}$ & \multicolumn{2}{|c|}{$S_{E}=-0.1 \rho_{L} \alpha_{L} \frac{T_{\text {mix }}-T_{\text {sat }}}{T_{\text {sat }}} L H$} \\
\hline & Condensation & $\mathrm{T}_{\text {mix }}<\mathrm{T}_{\text {sat }}$ & \multicolumn{2}{|c|}{$S_{E}=0.1 \rho_{V} \alpha_{V} \frac{T_{\text {sat }}-T_{\text {mix }}}{T_{\text {sat }}} L H$} \\
\hline
\end{tabular}

Table 2: Grid-independence results

\begin{tabular}{|l|l|l|l|}
\hline Mesh size (cells) & 19,603 & $\mathbf{6 9 , 0 9 2}$ & 87,800 \\
\hline $\mathrm{T}_{\text {evap av }}(\mathrm{K})$ & 378.71 & $\mathbf{3 7 8 . 3 7}$ & 378.19 \\
\hline $\mathrm{T}_{\text {cond av }}(\mathrm{K})$ & 326.54 & $\mathbf{3 2 6 . 9 6}$ & 327.79 \\
\hline $\mathrm{R}_{\text {CFD }}(\mathrm{K} / \mathrm{W})$ & 0.3017 & $\mathbf{0 . 2 9 7 4}$ & 0.2915 \\
\hline
\end{tabular}

Table 3: Condenser heat transfer coefficients for different heat inputs

\begin{tabular}{|c|c|c|c|c|}
\hline Evaporator & $\begin{array}{c}\text { Condenser } \\
\text { cooling } \\
\text { water }\end{array}$ & \multicolumn{3}{|c|}{ Condenser } \\
\hline $\mathrm{Q}_{\text {in }}$ & $\mathrm{T}_{\infty}$ & $\mathrm{Q}_{\mathrm{c}}$ & $\mathrm{T}_{\mathrm{c} \text { av }}$ & $\mathrm{h}_{\mathrm{c}}$ \\
\hline $\mathrm{W}$ & $\mathrm{K}$ & $\mathrm{W}$ & $\mathrm{K}$ & $\mathrm{W} / \mathrm{m}^{2} . \mathrm{K}$ \\
\hline 100.41 & 298.9 & 95.1 & 312.41 & 509.3 \\
\hline 172.87 & 301.45 & 162.6 & 318.07 & 707.6 \\
\hline 225.25 & 302.95 & 192.2 & 320.55 & 790.1 \\
\hline 275.60 & 305.2 & 236.6 & 325.95 & 824.9 \\
\hline 299.52 & 306.3 & 254.8 & 323.91 & 1046.6 \\
\hline 376.14 & 309.4 & 336.6 & 330.33 & 1163.5 \\
\hline
\end{tabular}


Table 4: Comparison between experimental data and CFD simulation for heat input of $172.87 \mathrm{~W}$

\begin{tabular}{|c|c|c|c|c|c|c|c|}
\hline \multirow{2}{*}{ Section } & \multirow{2}{*}{ Position } & $\mathrm{T}_{\mathrm{EXP}}$ & $\mathrm{T}_{\mathrm{CFD}}$ & $\mathrm{R}_{\mathrm{E}}$ & $\mathrm{T}_{\text {EXP av }}$ & $\mathrm{T}_{\text {CFD av }}$ & $\mathrm{R}_{\mathrm{E} \text { av }}$ \\
\hline & & K & K & $\%$ & $\mathrm{~K}$ & K & $\%$ \\
\hline \multirow{2}{*}{ Evaporator } & $\mathrm{Te}_{1}$ & 345.75 & 378.33 & 9.42 & \multirow{2}{*}{341.6} & \multirow{2}{*}{378.37} & \multirow{2}{*}{10.78} \\
\hline & $\mathrm{Te}_{2}$ & 337.45 & 378.40 & 12.14 & & & \\
\hline Adiabatic & Ta & 327.45 & 362.41 & 10.68 & & & 10.68 \\
\hline \multirow{5}{*}{ Condenser } & $\mathrm{Tc}_{1}$ & 320.55 & 329.54 & 2.80 & \multirow{5}{*}{318.07} & \multirow{5}{*}{326.96} & \multirow{5}{*}{2.80} \\
\hline & $\mathrm{Tc}_{2}$ & 318.85 & 326.54 & 2.41 & & & \\
\hline & $\mathrm{Tc}_{3}$ & 317.95 & 325.95 & 2.52 & & & \\
\hline & $\mathrm{Tc}_{4}$ & 317.05 & 325.64 & 2.71 & & & \\
\hline & $\mathrm{Tc}_{5}$ & 315.95 & 327.13 & 3.54 & & & \\
\hline
\end{tabular}

Table 5: Comparison between experimental data and CFD simulation for heat input of $376.14 \mathrm{~W}$

\begin{tabular}{|c|c|c|c|c|c|c|c|}
\hline \multirow{2}{*}{ Section } & \multirow{2}{*}{ Position } & $\mathrm{T}_{\mathrm{EXP}}$ & $\mathrm{T}_{\mathrm{CFD}}$ & $\mathrm{R}_{\mathrm{E}}$ & $\mathrm{T}_{\text {EXP av }}$ & $\mathrm{T}_{\mathrm{CFD} \mathrm{av}}$ & $\mathrm{R}_{\mathrm{E} \text { av }}$ \\
\hline & & K & $\mathrm{K}$ & $\%$ & $\mathrm{~K}$ & $\mathrm{~K}$ & $\%$ \\
\hline \multirow{2}{*}{ Evaporator } & $\mathrm{Te}_{1}$ & 376.75 & 385.14 & 2.23 & \multirow{2}{*}{370.2} & \multirow{2}{*}{385.05} & \multirow{2}{*}{4.01} \\
\hline & $\mathrm{Te}_{2}$ & 363.65 & 384.97 & 5.86 & & & \\
\hline Adiabatic & $\mathrm{Ta}$ & 342.75 & 370.11 & 7.98 & & & 7.98 \\
\hline \multirow{5}{*}{ Condenser } & $\mathrm{Tc}_{1}$ & 328.95 & 327.12 & 0.56 & \multirow{5}{*}{330.33} & \multirow{5}{*}{323.96} & \multirow{5}{*}{1.92} \\
\hline & $\mathrm{Tc}_{2}$ & 325.55 & 323.66 & 0.58 & & & \\
\hline & $\mathrm{Tc}_{3}$ & 332.45 & 323.15 & 2.80 & & & \\
\hline & $\mathrm{Tc}_{4}$ & 331.35 & 322.70 & 2.61 & & & \\
\hline & $\mathrm{Tc}_{5}$ & 333.35 & 323.17 & 3.05 & & & \\
\hline
\end{tabular}

Table 6: Comparison between experimental data and CFD simulation for different heat inputs

\begin{tabular}{|c|c|c|c|c|c|c|c|c|c|c|c|}
\hline Source & \multicolumn{3}{|c|}{ Evaporator } & \multicolumn{3}{c|}{ Adiabatic } & \multicolumn{3}{c|}{ Condenser } & \multicolumn{2}{c|}{$\begin{array}{c}\text { Thermal } \\
\text { Resistance }\end{array}$} \\
\hline $\mathrm{Q}_{\mathrm{in}}$ & $\begin{array}{c}\mathrm{Te}_{\mathrm{av}} \\
\mathrm{EXP}\end{array}$ & $\begin{array}{c}\mathrm{Te}_{\mathrm{av}} \\
\mathrm{CFD}\end{array}$ & $\mathrm{R}_{\mathrm{E}}$ & $\begin{array}{c}\mathrm{Ta} \\
\mathrm{EXP}\end{array}$ & $\begin{array}{c}\mathrm{Ta} \\
\mathrm{CFD}\end{array}$ & $\mathrm{R}_{\mathrm{E}}$ & $\begin{array}{c}\mathrm{Tc}_{\mathrm{av}} \\
\mathrm{EXP}\end{array}$ & $\begin{array}{c}\mathrm{Tc}_{\mathrm{av}} \\
\mathrm{CFD}\end{array}$ & $\mathrm{R}_{\mathrm{E}}$ & $\mathrm{R}_{\mathrm{EXP}}$ & $\mathrm{R}_{\mathrm{CFD}}$ \\
\hline $\mathrm{W}$ & $\mathrm{K}$ & $\mathrm{K}$ & $\%$ & $\mathrm{~K}$ & $\mathrm{~K}$ & $\%$ & $\mathrm{~K}$ & $\mathrm{~K}$ & $\%$ & $\mathrm{~K} / \mathrm{W}$ & $\mathrm{K} / \mathrm{W}$ \\
\hline 100.41 & 343 & 376.18 & 9.67 & 321.25 & 363.25 & 13.07 & 312.412 & 328.35 & 5.10 & 0.3046 & 0.4763 \\
\hline 172.87 & 341.6 & 378.37 & 10.76 & 327.45 & 362.41 & 10.68 & 318.07 & 326.96 & 2.80 & 0.1361 & 0.2974 \\
\hline 225.25 & 348.1 & 379.92 & 9.14 & 331.05 & 364.94 & 10.24 & 320.55 & 323.47 & 0.91 & 0.1223 & 0.2506 \\
\hline 275.6 & 356.1 & 381.6 & 7.16 & 335.55 & 365.62 & 8.96 & 325.95 & 327.36 & 0.43 & 0.1094 & 0.1967 \\
\hline 299.52 & 358.75 & 382.41 & 6.60 & 336.25 & 365.46 & 8.69 & 323.91 & 324.81 & 0.28 & 0.1163 & 0.1923 \\
\hline 376.14 & 370.2 & 385.06 & 4.01 & 342.75 & 370.11 & 7.98 & 330.33 & 323.96 & 1.93 & 0.1060 & 0.1624 \\
\hline Average relative error \% & 7.89 & & & 9.94 & & & 1.91 & & \\
\hline
\end{tabular}


Figures

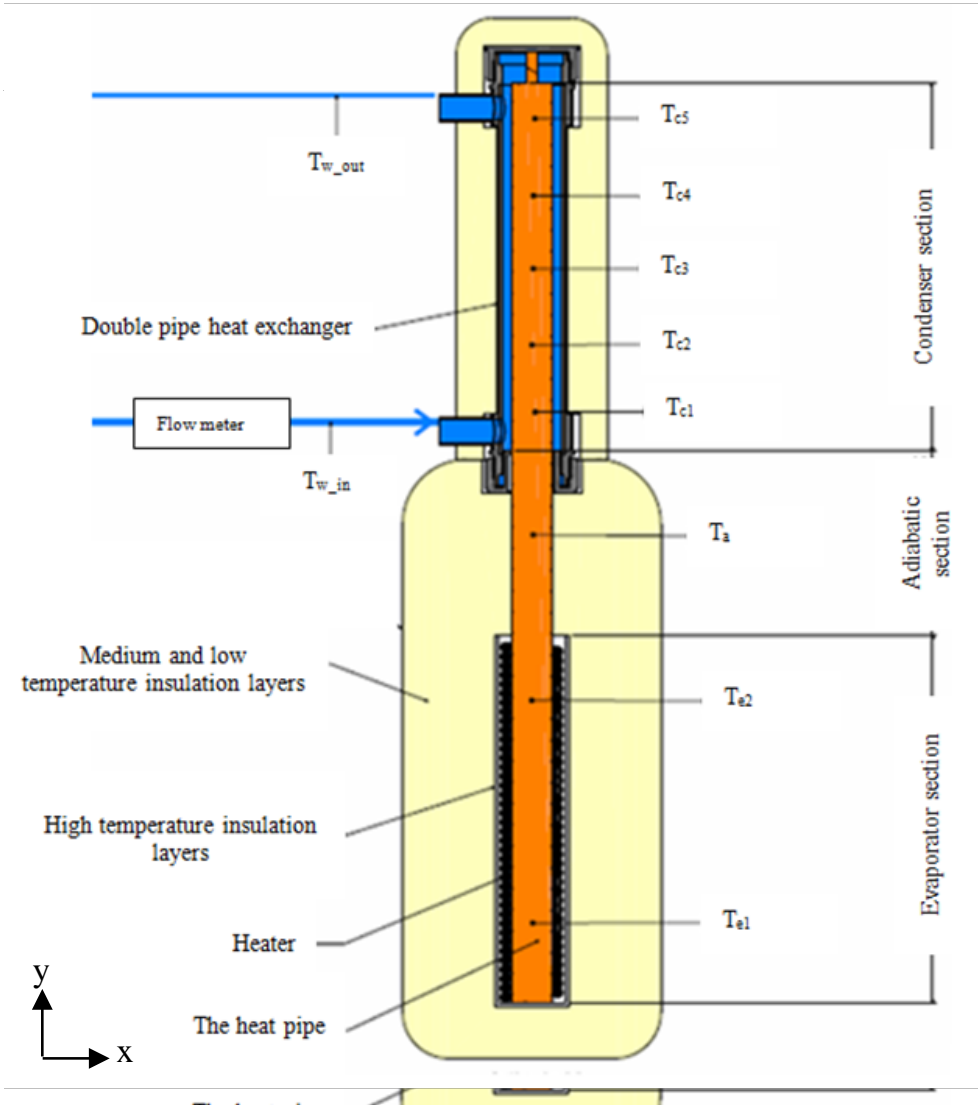

Figure 1: The experimental apparatus 


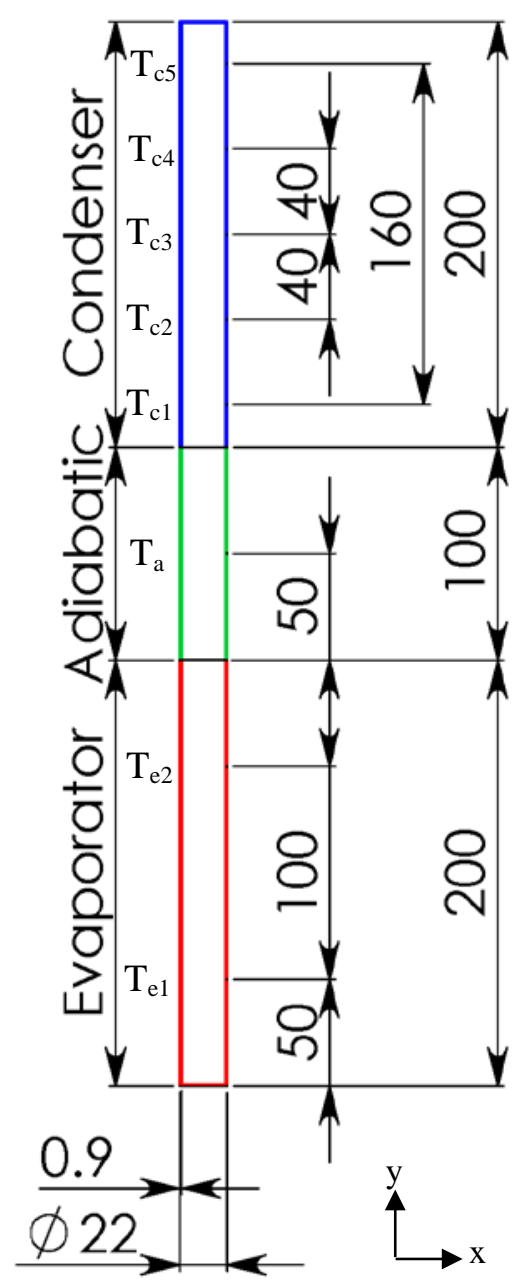

Figure 2: Geometry and dimensions 


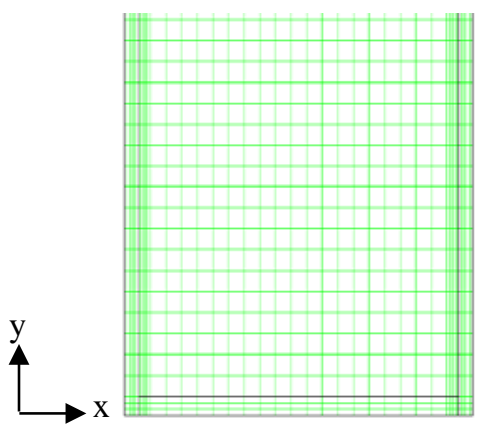

19,603

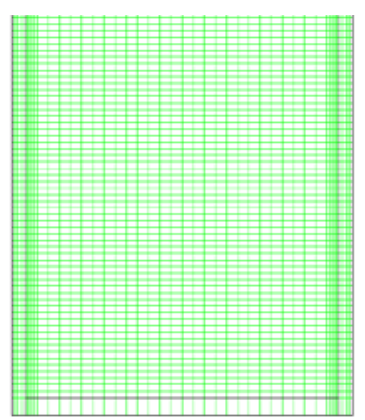

69,092

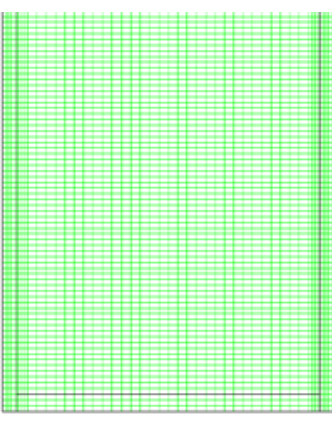

87,800

Figure 3: A section of the computational mesh 


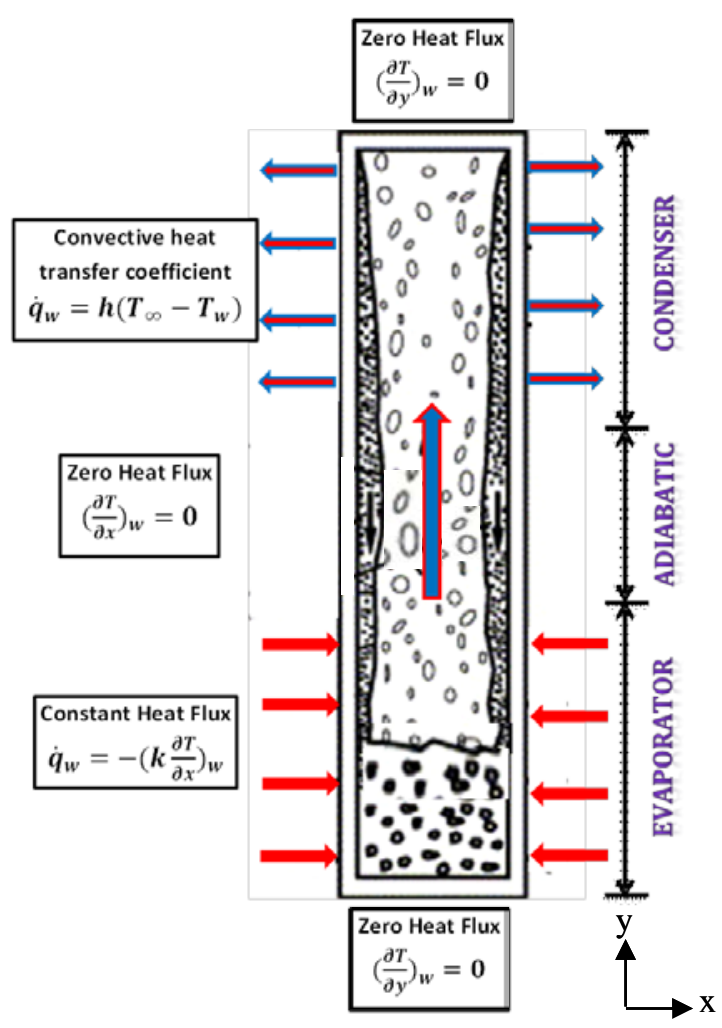

Figure 4: Boundary conditions of the thermosyphon 

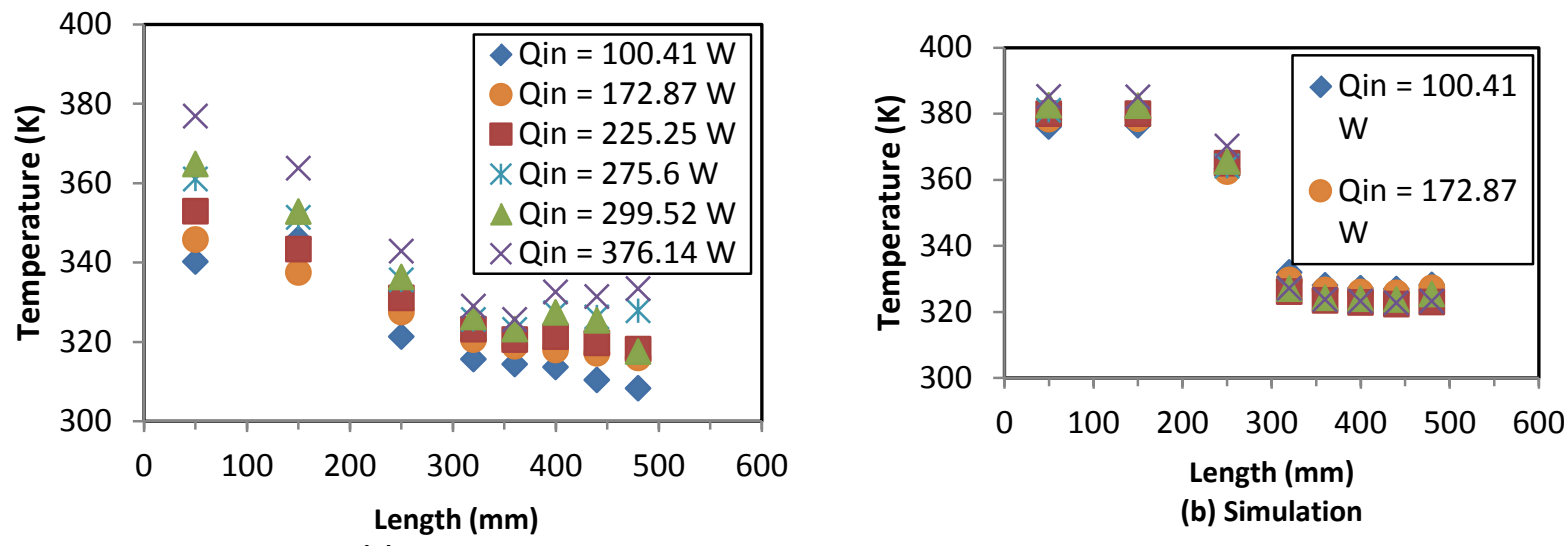

(a) Experiment

Figure 5: Temperature comparison between experiments and simulations for different heat inputs 


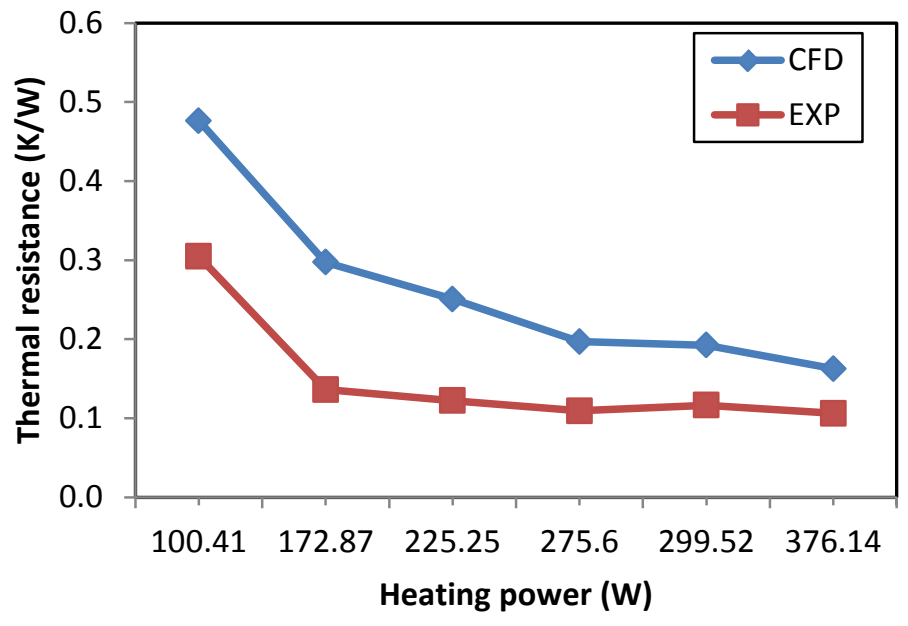

Figure 6: Relationship between thermal resistance and heating power 


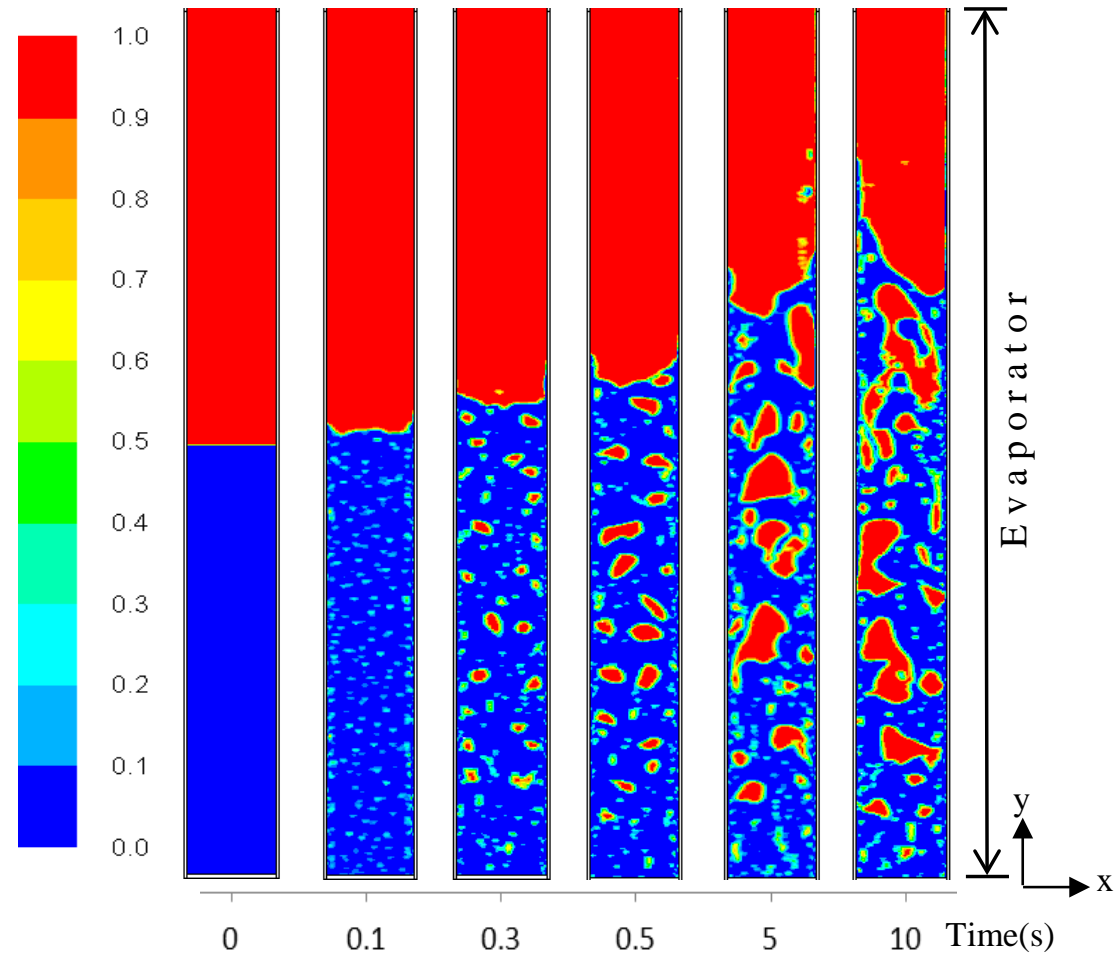

Figure 7: Contours of volume fraction of pool boiling in the evaporator section at different times 


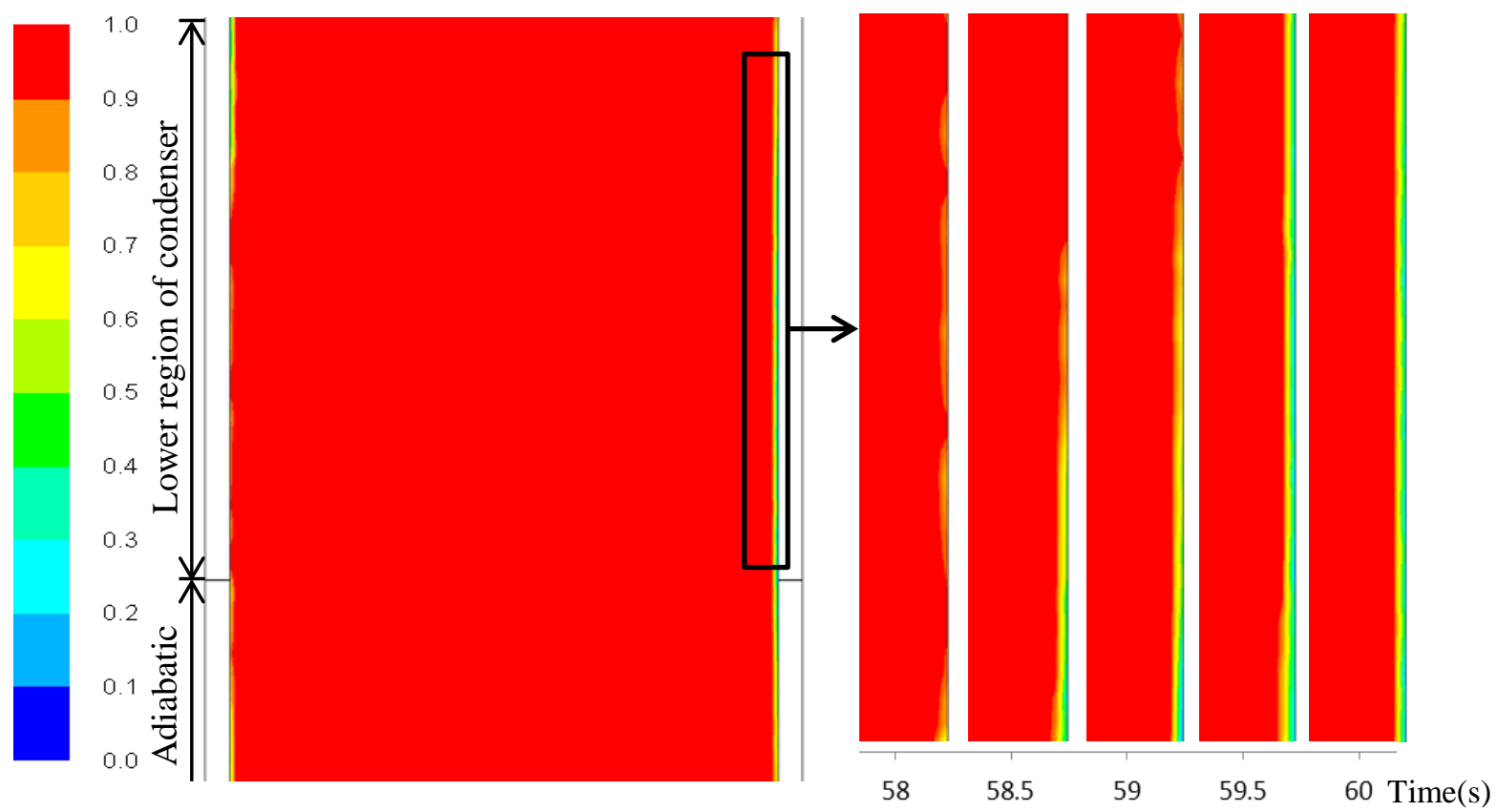

Figure 8: Contours of volume fraction of condensed liquid film in the lower region of condenser at different times 


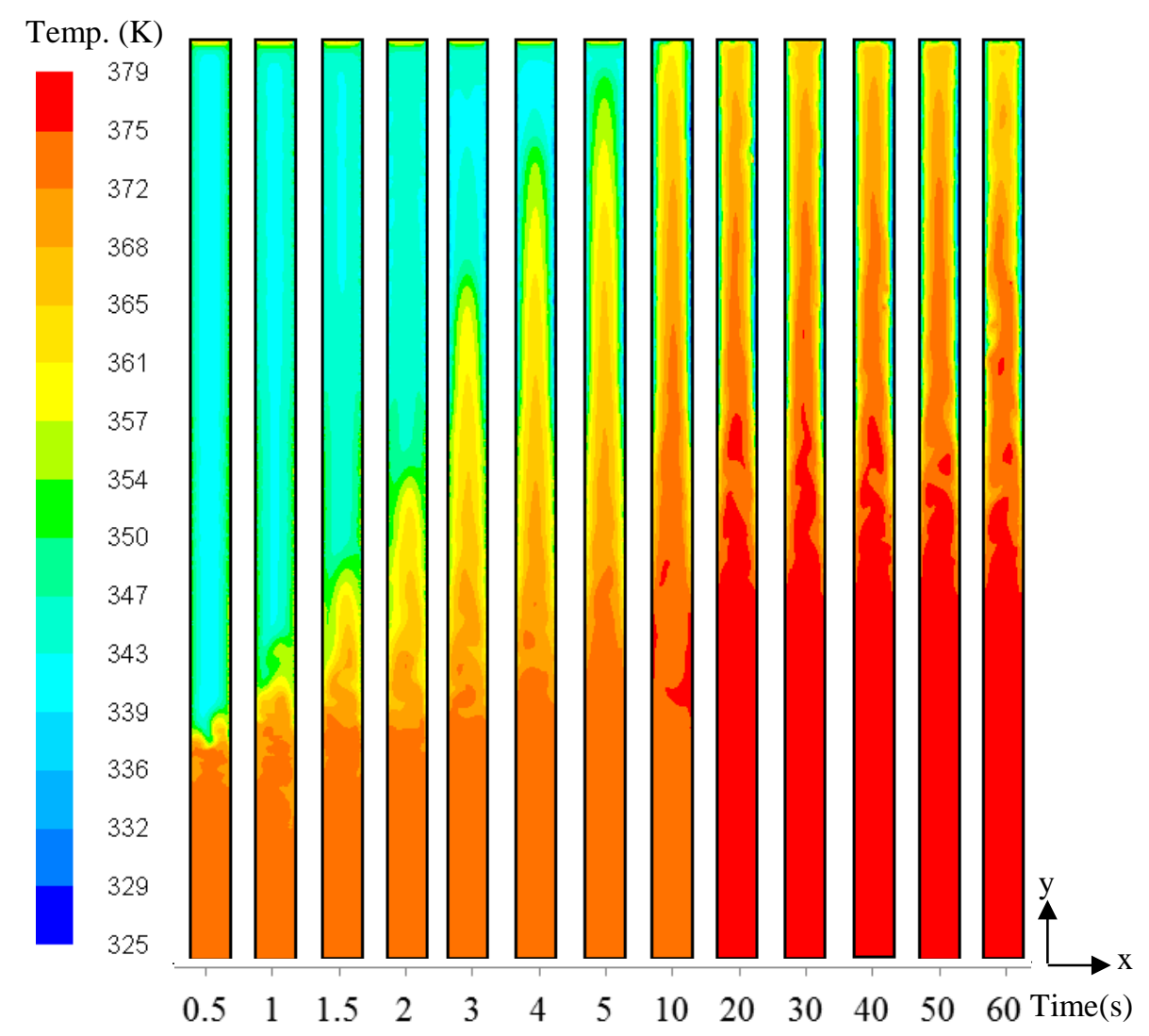

Figure 9: Temperature contours at different times 